\title{
Competitive Swimming and Racial Disparities in Drowning
}

\author{
Samuel L. Myers $\mathrm{Jr}^{1} \cdot$ Ana Cuesta $^{2} \cdot$ Yufeng Lai $^{3}$
}

Published online: 10 May 2017

(C) Springer Science+Business Media New York 2017

\begin{abstract}
This paper provides evidence of an inverse relationship between competitive swimming rates and drowning rates using Centers for Disease Control and Prevention (CDC) data on fatal drowning rates and membership rates from USA Swimming, the governing organization of competitive swimming in the United States. Tobit and Poisson regression models are estimated using panel data by state from 1999 to 2007 separately for males, females, African Americans and whites. The strong inverse relationship between competitive swimming rates and unintentional deaths through fatal drowning is most pronounced among African Americans males.
\end{abstract}

Keywords Swimming · Drowning · Racial disparities · Underrepresentation

A paper prepared for presentation at the 10th Biennial Pacific Rim Conference, Western Economic Association, International, March 14-17, 2013, Tokyo, Japan. Previous versions of the paper were presented at the APPAM Fall Research Conference, "Policy Analysis and Public Management in an Age of Scarcity: The Challenges of Assessing Effectiveness," November 8-10, 2012, Baltimore, MD., the Southern Economics Association Meetings, November 16-18, 2012, New Orleans, LA. The paper was also presented at the Population Association of America Meetings, May 1-3, 2014, Boston, MA. The authors express their gratitude for the many detailed comments and suggestions provided by seminar participants and reviewers.

Samuel L. Myers, Jr

myers006@umn.edu

Ana Cuesta

cuest003@umn.edu

Yufeng Lai

laixx214@umn.edu

1 Roy Wilkins Center for Human Relations and Social Justice, University of Minnesota, 263

Humphrey Center, 301 19th Avenue South, Minneapolis, MN 55455, USA

2 Department of Applied Economics, University of Minnesota, 316A Ruttan Hall, 1994 Buford Avenue, St. Paul, MN 55108, USA

3 Minnesota Population Center and Department of Applied Economics, University of Minnesota, 212 Ruttan Hall, 1994 Buford Avenue, St. Paul, MN 55108, USA 


\section{Introduction}

Accidental drowning is a leading cause of death among African American ${ }^{1}$ youth. Much has been written about segregated swimming pools as a source of reproduction of inequality and a contributor to current patterns of racial disparities in drowning (DeLuca 2013; Wiltse 2014). The conventional wisdom is that the legacy of segregated swimming pools contributes to the lack of access that African Americans have to learnto-swim programs and thereby attenuates the racial gap in drowning rates (Wiltse 2007, 2014). Undisputed is that there is a low rate of self-reported ability to swim among African Americans (Irwin et al. 2011). Aside from or perhaps in conjunction with the absence of access to swimming facilities is the reportedly high rates of fear of drowning among black mothers, who coincidentally may thwart interest in swimming among their children (Irwin et al. 2011).

An alternative hypothesis is that black drowning rates are linked to black participation in competitive swimming. The economic mechanism linking these two is the labor market for lifeguards and the positive effect of concentrations of black lifeguards on reversing or containing forces that discourage blacks from learning how to swim. This paper offers the first empirical demonstration of the inverse relationship between black participation in competitive swimming that helps to reduce drowning rates. The empirical effects are robust across alternative model specifications and estimation strategies.

This paper builds a unique data set from existing sources that will contribute to the understanding of the relationship between a) racial disparities in accidental drowning, and b) underrepresentation of blacks among competitive swimmers. It provides evidence of a strong empirical relationship between two closely aligned phenomena: racial disparities in elite participation in one sport and racial disparities in a significant health outcome: accidental drowning.

The paper proceeds in the following manner. First, the problem of racial disparities in drowning is outlined and evidence is presented about the health benefits associated with the promotion of swimming. Then, a heuristic model is sketched linking the labor market for lifeguards to competitive swimming and connecting competitive swimming rates to drowning rates. The rationale for the model specification and estimation is provided along with the data used to produce the strong inverse relationship between competitive swimming rates and drowning rates. The results follow. In a concluding discussion section, concerns about the causal path leading to the observed inverse relationship are detailed along with suggestions for future research.

\section{Background}

The Centers for Disease Control and Prevention (CDC) report that drowning is the second leading cause of unintentional injury-related death for children between the ages of 1 and 14. Between 2000 and 2007, the fatal unintentional drowning rate for African Americans across all ages was 1.3 times that of whites. The fatal drowning rate of

\footnotetext{
${ }^{1}$ The authors of this paper adopt the convention of using the terms "African American" and "black" interchangeably.
} 
African American children ages 5 to 14 is 3.1 times that of white children in the same age range (Centers for Disease Control and Prevention 2011).

The most comprehensive source of information on drowning comes from the CDC. Only limited statistical analysis of this important data set has been undertaken to date. CDC researchers themselves conducted the most important of these analyses and provided the most accurate description of drowning rates by race, state and gender (Brenner and Committee on Injury, Violence, and Poison Prevention 2003; Brenner et al. 2003; Brenner et al. 2009; Borse et al. 2008). Micro-level analyses of these data have yielded valuable insights about the sources of drowning rates and reporting of drowning rates among infants and toddlers. One of the key findings from these valuable contributions and carefully conducted micro-level studies is that we really do not know why there are such wide racial disparities in drowning other than the fact that blacks are far more likely than whites to report an inability to swim. Thus, the two main explanations offered for why there are racial disparities in drowning rates are: a) racial differences in swimming ability; and b) racial differences in access to swimming pools or swim training programs (Hastings et al. 2006; Saluja et al. 2006).

Research on the relationship between swimming ability and drowning rates has produced conflicting evidence (Brenner et al. 2003). Brenner et al. (2009) found that among those under 5, drowning rates were higher for those who had no previous instruction in swimming. However, there were no statistically significant impacts of swimming instruction on drowning rates for 5 to 19 year olds. This difference may arise because older children and teenagers with only limited swimming instruction might overestimate their swimming ability and place themselves at greater risk than those with no swimming instruction at all. That is why one might expect the instruction threshold for reducing drowning rates among older children to be much higher than it is among younger children. This insight is one of the motivations in this paper for examining competitive swimming rates and drowning among older children.

Fatal drownings can be prevented. Clearly, there are health benefits associated with prevention and reduction of drownings. The health benefits associated with reductions in drowning rates are twofold. First, prevention of drowning saves lives. Second, when drowning rates are reduced through improved swimming ability, there is an additional health benefit: swimming is considered one of the best forms of physical exercise with numerous cardiovascular benefits (Thompson et al. 2003). It is a life-long sport that is associated with many positive healthy living outcomes (Stephens 1988). Swim training reduces obesity (Murase et al. 2006; Scomparin et al. 2006), reduces adverse effects associated with diabetes (de Oliveira et al. 2007), and has the potential for ameliorating the impacts of asthma (Rosimini 2003). Additionally, swimming and swim training have the potential for reducing racial disparities in health outcomes because African Americans are more likely than whites to be obese (Cossrow 2004), to have diabetes, to suffer from end-stage renal disease (Cowie et al. 1989), and to suffer from early childhood asthma (Miller 2000).

Despite the many health benefits associated with swimming, black youth are severely underrepresented in what is known to be one of the most popular recreational and competitive sports among whites. USA Swimming, the primary organization of competitive swimming among age-group swimmers who have not reached college and the central pipeline for Olympic hopefuls in the United States, reported that only $0.87 \%$ 
of its members were African American (USA Swimming 2005). ${ }^{2}$ African Americans are severely underrepresented in competitive swimming despite their overrepresentation in sports overall (Myers 2011; Myers 1998; Hoberman 1997).

There are a large number of myths about why blacks are underrepresented among swimmers. The myths range from the biology of physical predisposition to running vs. swimming (Bejan et al. 2010) to a large variety of cultural explanations - black females do not like to get their hair wet or black males do not like to wear Speedos (Irwin et al. 2009a). Researchers have demonstrated that many of these myths cannot be validated in interviews or surveys of minority swimmers themselves (Irwin et al. 2008, 2009a, b, 2010).

An official report of the American Academy of Pediatrics clearly admits that there is much that we do not know about racial disparities in drowning and the linkage to other factors such as swimming ability. Jeffrey Weiss (2010, p. e254) writes:

The reasons that black children and teenagers are more likely to drown are not clear, but poor parental swimming skills, lack of early training, poor swimming ability, and lack of lifeguards at motel/hotel pools may be important factors.

\section{Model}

A heuristic labor market model that provides a plausible narrative linking black drowning rates to black participation in competitive swimming is the following: when there are more minority swimmers on teams or in programs that offer training for lifeguards, the supply of minority lifeguards increases. Minority lifeguards are more likely to be employed in pools and recreation areas where there are large numbers of minority customers. Where there are more well-trained and competent lifeguards there should be fewer drownings. Relatedly, the relative dominance of swimming in a local market area is captured by the degree to which teenagers invest in developing advanced skills in a particular sport and thereby become eligible for employment in sports-related occupations during their teenage years. Lifeguarding, it is well-known, is one of the most popular sources of summer employment for competitive swimmers. The workplace is often precisely the same as the training facility; the skill sets required are conditional upon having specialized training almost universally available to competitive swimmers. In some states, such as Minnesota, ${ }^{3}$ swimming is one of the most popular sports for teenage females, and as a result, disproportionate shares of lifeguards in that market are female. This dominance of swimming as a competitive sport increases the supply of lifeguards, increases the pool of persons who have swimming ability, and arguably, is associated with lower drowning rates. Other sports, such as basketball, football, or track may be less amenable to increasing the relative supply of persons with swimming ability.

To model the relationship between competitive swimming and drowning rates, this paper assembles a panel data set combining annual data by state, gender, race and

\footnotetext{
${ }^{2}$ Time standards for 2009-2012 were set for the following age groups: Under-10; $11-12 ; 13-14 ; 15-16$; and 17-18.

${ }^{3}$ In 2012, 62.94\% of the competitive swimmers in Minnesota were females (USA Swimming 2012).
} 
ethnicity on (a) membership in the USA Swimming and (b) data on unintentional drowning from the CDC for children 7 to 18 .

The dependent variable is a measure of unintentional drownings, $\delta_{\mathrm{jt}}$, in the $j$ th state, race, gender group for the $t$-th year. It is a function of a vector of weather, geographic, social and demographic factors, $X$, as well as a measure of competitive swimming participation $\sigma_{j t}$.

$$
\delta_{j t}=f\left(\sigma_{j t} ; X_{j t}\right)+\mu_{j t}
$$

where $X$ denotes a host of predictors of drowning disproportionalities and $\sigma_{j t}$ captures participation in the USA Swimming Association and where the error term, $\mu$, is assumed to be normally distributed with standard properties.

\section{Data}

Two variables are critical for our analysis: fatal unintentional drowning and competitive swimming participation rates. The information on fatal unintentional drowning comes from the CDC. ${ }^{4}$ Public data by state, gender, and race was retrieved from the Fatal Injury Reports 1999-2007. We use data for non-Hispanic white and African American children, 7 to 18 years of age for each state and each year. ${ }^{5}$

Data on competitive swimming participation by gender and race comes from the Membership Statistics Reports of USA Swimming, the governing organization of youth competitive swimming in the United States. To compute the participation rates for non-Hispanic white and African American children, we used as reference the "YearRound Athlete Membership_Ethnicity" tables. ${ }^{6}$ Data on ethnicity-race is available by Local Swimming Committees (LSC); we transformed this data to aggregate it at the state level (for example, Texas and California have multiple LSCs). Race is a selfreported variable in the USA Swimming Reports: on average $25 \%$ of the female athletes do not report their race; for the case of male athletes, the average is $15 \%$.

\footnotetext{
${ }^{4}$ Fatal unintentional drowning means accidental deaths due to drowning or submersion. Excluded are homicides, suicides, or drowning deaths arising from legal intervention or war.

https://www.cdc.gov/nchs/data/ice/icd10_transcode.pdf

The CDC definition of fatal unintentional drownings includes: drowning and submersion while in bath-tub; drowning and submersion following fall into bath-tub; drowning and submersion while in swimming-pool; drowning and submersion following fall into swimming-pool; drowning and submersion while in natural water, including lakes, the open sea, rivers and streams; drowning and submersion following fall into natural water; or specified drowning and submersion, including quenching tanks and reservoirs. The CDC definition excludes cataclysm, transport accidents, and water transport accidents and such watercraft accidents in the course of recreational activities as overturning or sinking of a boat or falling or jumping from a burning ship or crushed watercraft. Water-transport-related drowning or submersion without accident to watercraft. The definition excludes drowning and submersion as a result of an accident, such as falling from gangplank, falling overboard, or thrown overboard by motion of ship, or washed overboard. Included in the definition, however, is drowning or submersion of a swimmer or diver who voluntarily jumps from a boat not involved in an accident.

https://www.cdc.gov/injury/wisqars/fatal help/data_sources.html

${ }^{5}$ Retrieved from the Data and Statistics (WISQARS) system: number of deaths, population and the crude death rates by race, gender, year and state.

${ }^{6}$ The Year-round Athlete Membership Report by year is available at www.usaswimming.org.
} 
The athletes' ages range from 7 to 18 . The competitive swimming participation rate was computed by using data from the USA Swimming Reports and the population data from the CDC reports, ${ }^{7}$ by state and year.

The empirical analysis includes additional variables that could influence the drowning rates, but do not affect the competitive swimming participation rates, such as weather and geography data. Hot weather could yield to a higher outdoor drowning risk (Fralick et al. 2013), to account for this, we used the mean summer temperature ${ }^{8}$ and cooling degree data ${ }^{9}$ per year by state as control variables related to weather, retrieved from the National Climatic Data Center-National Oceanic and Atmospheric Administration (NCDC-NOAA). Geography data was incorporated to consider the fact that not all drownings occur in environments and activities supervised by lifeguards. Therefore, we included data on the percentage of water area by state, retrieved from the United States Geological Survey (USGS) website, ${ }^{10}$ and data on miles of coastlines by state, retrieved from the Ocean and Coastal Resource Management-NOAA. ${ }^{11}$ The measure we use incorporates data on rivers, lakes, sounds, bays and other waterways.

Additional control variables by state and year, such as population density, income per capita, and percent population with college degrees was retrieved from the Statistical Abstracts of the United States-U.S. Census Bureau.

\section{Descriptive Results}

Combining the state level drowning rates with the swimming participation rates by race, we produce the source of information for the empirical regularity displayed in Fig. 1, the scatter plot of the percent of USA Swimming swimmers who are black against the number of accidental drowning deaths per 100,000 across the 30 states that had at least one black drowning death in the year 2000. The log-log equation fitting the plot of black shares of competitive swimmers to the black drowning rate per 100,000 produces an R-square of 0.124 , a constant term of .0308 , and an estimated coefficient on black shares of competitive swimmers equal to -0.208 , which is statistically significant at the $5 \%$ level (one-tailed test). The interpretation is that a $1 \%$ increase in the black share of competitive swimmers reduces black drowning rates by about one fifth of $1 \%$. The effect is inelastic and not on a large order of magnitude, but it is statistically significant. This is very elementary evidence of the inverse relationship between black drowning and diversity in competitive swimming that is hypothesized in this paper. These preliminary results are only for one year, for one way of measuring diversity.

Exclusion of states with zero black drowning rates - at times, 1/3 of all states in the nation - could produce skewed results. To accommodate the fact that drowning is a rare and censored event, with a lower bound of zero, we have adopted a Tobit model with fixed effects to capture the zero drowning events in some states and years. From the

\footnotetext{
${ }^{7}$ Population data provided by the CDC is from the U.S. Census Bureau interim population projections.

${ }^{8}$ The mean summer temperatures (in Fahrenheit scale) were estimated by computing the average temperature for the months of June, July and August. Source: https://www.ncdc.noaa.gov/cag/time-series/us.

9 The cooling degree index reflects the demand of energy to cool houses and business when the temperatures are higher than $65 \mathrm{~F}$ degrees. Source: https://www7.ncdc.noaa.gov/CDO/CDODivisionalSelect.jsp\#.

${ }^{10} \mathrm{http}: / /$ ga.water.usgs.gov/edu/wetstates.html

$11 \mathrm{http} / /$ coastalmanagement.noaa.gov/mystate/welcome.html
} 


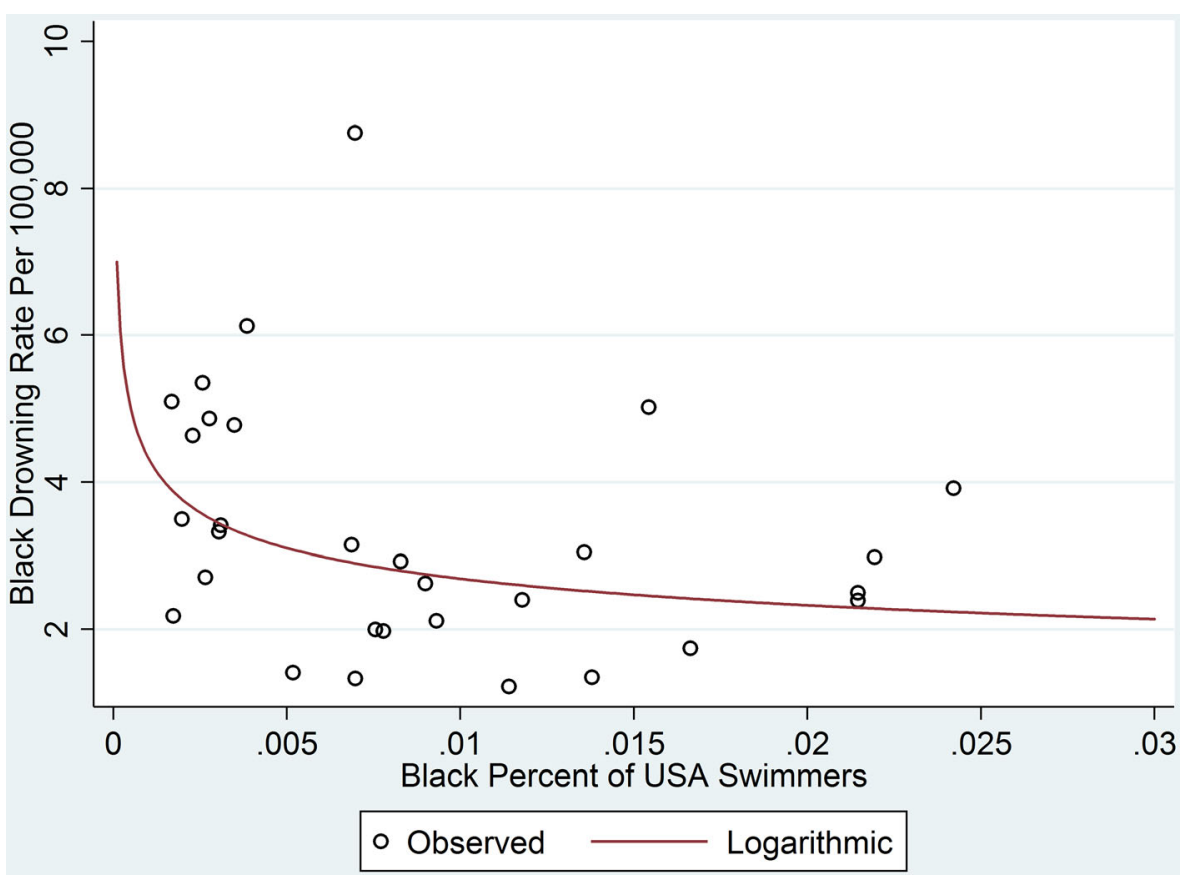

Fig. 1 Black drowning rate per 100,000 Source: Authors' calculations from merged time series cross-sectional data, Drowning in US Swimming

1008 observations on unintentional drowning, disaggregated by race and gender, $40.16 \%$ are zeros, $34.31 \%$ of the cases are between 1 and 3 unintentional drowning and less than $4 \%$ report more than ten events. ${ }^{12}$

The Tobit model takes the form

$$
\delta_{j t}{ }^{*}=\beta \sigma_{j t}+X_{j t}^{\prime} \gamma+\varepsilon_{j t}
$$

where the drowning variable is censored to the left. The interpretation of the $\beta$ coefficient is a partial derivative of drownings with respect to the competitive swimming rates. In order to provide a coefficient that could be interpreted as the change in drowning events that can be explained by a small increase in competitive swimming rates, we report the marginal effects in the results section. When this coefficient is negative, it means that increases in competitive swimming reduce drowning events. When this coefficient is positive, it means that increases in competitive swimming increase drowning events.

\section{The Model Estimation Results}

Table 1 summarizes the results of the Tobit model for aggregated specifications, for the whole sample and separately for males, females, blacks and whites, using a Tobit fixed effects model. Fixed effects are capture by dummy variables for eight different US Census

\footnotetext{
${ }^{12}$ When disaggregating by race and gender, the proportion of observation with zero drowning is: $70.6 \%$ for black females, $42.5 \%$ for black males, $53.18 \%$ for white females, and $18.3 \%$ for white males.
} 
Table 1 Estimated coefficients of the effect of competitive swimming rates on drowning from Tobit fixed effects regression

\begin{tabular}{|c|c|c|c|c|c|}
\hline Variables & All & Males & Females & Blacks & Whites \\
\hline \multirow[t]{2}{*}{ Swimmers Rate } & 0.8933 & -2.2873 & 1.0360 & $-20.1234 * * *$ & 0.4650 \\
\hline & {$[0.968]$} & [1.907] & [0.693] & [4.993] & {$[1.117]$} \\
\hline \multirow[t]{2}{*}{ State Water Percentage } & $2.4390 * *$ & $4.1191 * * *$ & 1.2038 & 1.1636 & $4.0773 * * *$ \\
\hline & [0.954] & {$[1.426]$} & {$[0.734]$} & [1.298] & [1.249] \\
\hline \multirow[t]{2}{*}{ Summer Mean Temperature } & 0.1124 & 0.0707 & $0.1912 * *$ & 0.0788 & 0.1898 \\
\hline & {$[0.097]$} & {$[0.146]$} & {$[0.082]$} & {$[0.148]$} & {$[0.118]$} \\
\hline \multirow[t]{2}{*}{ Cooling Degree Days (CDD) } & $0.0123 * *$ & $0.0179 * *$ & 0.0013 & $0.0148^{* *}$ & 0.0077 \\
\hline & {$[0.005]$} & {$[0.007]$} & {$[0.004]$} & {$[0.007]$} & {$[0.006]$} \\
\hline \multirow[t]{2}{*}{ Coast Line (miles) } & $0.0004 *$ & 0.0002 & 0.0002 & $0.0007 * *$ & 0.0001 \\
\hline & {$[0.000]$} & {$[0.000]$} & {$[0.000]$} & {$[0.000]$} & {$[0.000]$} \\
\hline \multirow[t]{2}{*}{ Female } & $-4.8729 * * *$ & & & $-5.0359 * * *$ & $-4.5796^{* * *}$ \\
\hline & {$[0.247]$} & & & {$[0.315]$} & {$[0.365]$} \\
\hline \multirow[t]{2}{*}{ Black } & -0.4888 & $-1.1031 * *$ & -0.2761 & & \\
\hline & {$[0.358]$} & {$[0.504]$} & {$[0.310]$} & & \\
\hline \multirow[t]{2}{*}{ Year } & $-0.4406^{* * *}$ & $-0.5070^{* * * *}$ & $-0.2560 * * *$ & $-0.4791 * * *$ & $-0.3861 * * *$ \\
\hline & {$[0.070]$} & {$[0.103]$} & {$[0.053]$} & [0.099] & {$[0.084]$} \\
\hline \multirow[t]{2}{*}{ Constant } & $868.8349 * * *$ & $1003.3409 * * *$ & $494.1764 * * *$ & $948.6713 * * *$ & $755.0230 * * *$ \\
\hline & [138.143] & [203.567] & [105.844] & [196.459] & [166.958] \\
\hline \multirow[t]{2}{*}{ Sigma } & $2.8768 * * *$ & $3.1019 * * *$ & $1.6712 * * *$ & $2.7132 * * *$ & $2.6543 * * *$ \\
\hline & {$[0.104]$} & {$[0.121]$} & [0.095] & {$[0.130]$} & {$[0.148]$} \\
\hline Observations & 1008 & 504 & 504 & 504 & 504 \\
\hline
\end{tabular}

Bold coefficients added for emphasis. Robust standard errors in brackets and italics $* * * p<0.01, * * p<0.05, * p<0.1$

Regions using New England as the reference category ${ }^{13}$ and sigma is the estimated standard error of the regression. The Appendix provides the full results of the regressions. Appendix Table 5 provides the full results of the Tobit model without using fixed effects.

The results confirm that blacks have higher drowning rates than whites, as evidenced by the larger intercept for blacks than for whites. The results also show that the effect of competitive swimming on unintentional drowning is negative, large and significant for blacks. A $1 \%$ age point increase in competitive swimming reduces unintentional drowning rates by 20.12 per 100,000 or about 0.02 percentage point (significant at the $1 \%$ level). The effects for whites alone, males alone or females alone are not statistically significant. In line with the findings of Fralick et al. (2013), higher temperatures have a positive impact on the unintentional drowning rates; for example an increase of one Fahrenheit degree in the mean summer temperature increases the unintentional drowning rate for females by 0.19 per 100,000 . Also, a larger proportion of water area or coastline mileage increases the probability of unintentional drowning

\footnotetext{
${ }^{13}$ New England, Middle Atlantic, East North Central, West North Central, South Atlantic, East South Central, West South Central, Mountain and Pacific.
} 
rates, which is associated with higher probabilities of swimming in areas that are not supervised by lifeguards.

Table 2 reproduces the substantive findings of Table 1 separately by race and gender.

The impacts of competitive swimming in the disaggregated model are almost exclusively concentrated among blacks. The effects of competitive swimming are large and statistically significant in the black male and black female equations and are larger for black males than they are for black females, further underscoring the fact that competitive swimming manifests itself in disparate ways by race and gender. Increasing competitive swimming among black males by one percentage point reduces the unintentional drowning events by 23.47 per 100,000 or about 0.02 percentage point (significant at the one percent level) while for black females, the same increase will reduce the drowning events by 8.04 per 100,000 or about 0.008 percentage point (significant at the $5 \%$ level). Among white males and females, competitive swimming does not have statistically significant effects on unintentional drowning. Additionally, the intercepts in the black male and black female equations are higher than those for white males and white females, confirming that base drowning rates are higher for blacks than whites.

Among white males and females, geographic and weather related variables are the ones that mainly explain the effects on unintentional drownings. For example, among white males, state water percentage is a large and statistically significant determinant of drowning rates. The mean summer temperature has a positive and significant effect on

Table 2 Estimated coefficients of the effect of competitive swimming rates on drowning from Tobit fixed effects regression by race and gender

\begin{tabular}{|c|c|c|c|c|}
\hline Variables & Black males & White males & Black females & White females \\
\hline Swimmers Rate & $\begin{array}{l}-\mathbf{2 3 . 4 7 2 6} * * * \\
{[7.580]}\end{array}$ & $\begin{array}{l}-\mathbf{0 . 3 3 8 4} \\
{[2.043]}\end{array}$ & $\begin{array}{l}-\mathbf{8 . 0 3 7 0 * * *} \\
{[3.552]}\end{array}$ & $\begin{array}{l}\mathbf{0 . 2 7 2 4} \\
{[0.810]}\end{array}$ \\
\hline State Water Percentage & $\begin{array}{l}2.0358 \\
{[1.796]}\end{array}$ & $\begin{array}{l}6.8435^{* * * *} \\
{[1.735]}\end{array}$ & $\begin{array}{l}0.9100 \\
{[0.919]}\end{array}$ & $\begin{array}{l}1.3712 \\
{[1.042]}\end{array}$ \\
\hline Summer Mean Temperature & $\begin{array}{l}0.0327 \\
{[0.205]}\end{array}$ & $\begin{array}{l}0.1739 \\
{[0.182]}\end{array}$ & $\begin{array}{l}0.1268 \\
{[0.118]}\end{array}$ & $\begin{array}{l}0.2360 * * \\
{[0.102]}\end{array}$ \\
\hline Cooling Degree Days (CDD) & $\begin{array}{l}0.0237 * * \\
{[0.010]}\end{array}$ & $\begin{array}{l}0.0086 \\
{[0.009]}\end{array}$ & $\begin{array}{l}-0.0009 \\
{[0.006]}\end{array}$ & $\begin{array}{l}0.0028 \\
{[0.006]}\end{array}$ \\
\hline Coast Line (miles) & $\begin{array}{l}0.0008^{*} \\
{[0.000]}\end{array}$ & $\begin{array}{l}-0.0004 \\
{[0.000]}\end{array}$ & $\begin{array}{l}-0.0000 \\
{[0.000]}\end{array}$ & $\begin{array}{l}0.0004 \\
{[0.000]}\end{array}$ \\
\hline Year & $\begin{array}{l}-0.5687 * * * \\
{[0.137]}\end{array}$ & $\begin{array}{l}-0.4332 * * * \\
{[0.118]}\end{array}$ & $\begin{array}{l}-0.2551^{* * *} \\
{[0.073]}\end{array}$ & $\begin{array}{l}-0.2519^{* * * *} \\
{[0.071]}\end{array}$ \\
\hline Constant & $\begin{array}{l}1129.5289^{* * * *} \\
{[270.868]}\end{array}$ & $\begin{array}{l}849.5229 * * * \\
{[233.446]}\end{array}$ & $\begin{array}{l}497.8071 * * * \\
{[144.353]}\end{array}$ & $\begin{array}{l}481.9563^{* * *} \\
{[139.376]}\end{array}$ \\
\hline Sigma & $\begin{array}{l}2.7104 * * * \\
{[0.150]}\end{array}$ & $\begin{array}{l}2.7382 * * * \\
{[0.171]}\end{array}$ & $\begin{array}{l}1.4951 * * * \\
{[0.103]}\end{array}$ & $\begin{array}{l}1.6621^{* * *} \\
{[0.134]}\end{array}$ \\
\hline Observations & 252 & 252 & 252 & 252 \\
\hline
\end{tabular}

Bold coefficients added for emphasis. Robust standard errors in brackets and italics $* * * p<0.01, * * p<0.05, * p<0.1$ 
white female drowning rates. An increase of one degree Fahrenheit leads to a 0.23 per 100,000 increase in unintentional drownings.

As shown in Table 6 in the appendix, the results are similar when disregarding the fixed effects in the different specifications. As an additional robustness check, we use an alternative specification to accommodate the fact that drowning is a rare event and that the occurrence of one event does not affect the probability that a second event will happen, thus our model could be taken as a count data model that could follow a Poisson distribution skewed to the left. The Poisson model takes the form of:

$$
\ln \left(\delta_{j t}\right)=\sum \beta_{j t} x_{j t}+s_{j t} \sigma_{j t}
$$

or

$$
\delta_{j t}=\prod e^{\beta_{j t} x_{j t}{ }^{*}} e^{s_{j t} \sigma_{j t}}
$$

The interpretation of the coefficient, $s$, is the percentage change in drownings per 100,000 that can be explained by an increase in competitive swimming rates. When this coefficient is negative, it means that increases in competitive swimming reduce drowning rates. When this coefficient is positive, it means that increases in competitive swimming increase drowning rates. Table 3 presents the results of the Poisson model separately by race and gender.

As before, the impacts of competitive swimming in the Poisson model are almost exclusively concentrated among blacks, although the size of the effect differs. The results show that a $1 \%$ increase in competitive swimming reduces drowning rates by

Table 3 Estimated coefficients of the effect of competitive swimming rates on drowning rates from Poisson regression

\begin{tabular}{lllll}
\hline Variables & Black males & White males & Black females & White females \\
\hline Swimmers Rate & $-\mathbf{6 . 9 4 1 8 * * *}$ & -0.3349 & $-\mathbf{9 . 7 5 2 0 * *}$ & -0.0393 \\
& {$[1.947]$} & {$[0.701]$} & {$[4.195]$} & {$[0.399]$} \\
State Water Percentage & $-1.4345^{* * * *}$ & -0.2084 & -1.1311 & $-0.5310^{* * *}$ \\
Summer Mean Temperature & {$[0.380]$} & {$[0.408]$} & {$[1.812]$} & {$[0.182]$} \\
& $-0.1368^{* * *}$ & -0.0365 & -0.0542 & -0.0105 \\
Cooling Degree Days (CDD) & {$[0.024]$} & {$[0.043]$} & {$[0.092]$} & {$[0.047]$} \\
Coast Line (miles) & 0.0023 & 0.0001 & -0.0004 & 0.0033 \\
& {$[0.002]$} & {$[0.002]$} & {$[0.004]$} & {$[0.004]$} \\
Year & 0 & -0.0001 & -0.0001 & $0.0003 * * *$ \\
& {$[0.000]$} & {$[0.000]$} & {$[0.000]$} & {$[0.000]$} \\
Observations & $-0.0779 *$ & -0.0015 & -0.1342 & $-0.1109 * *$ \\
Number of Census Regions & $70.045]$ & {$[0.025]$} & {$[0.084]$} & {$[0.052]$} \\
\hline
\end{tabular}

Bold coefficients added for emphasis. Robust standard errors in brackets and italics $* * * p<0.01, * * p<0.05, * p<0.1$ 
about $6.94 \%$ (significant at the $1 \%$ level) for black males and $9.75 \%$ (significant at the $5 \%$ level) for black females. The results for whites are small and insignificant, but with this model, the coefficients are negative for both male and female.

Table 7 in the Appendix reports the results for the full Poisson model. From our estimations, we can conclude that the impacts of competitive swimming are almost exclusively concentrated among blacks.

We have also conducted Granger-Simms causality tests to determine whether the results are the consequence of past drowning rates influencing rates of competitive swimming. The possibility exists that a fear of drowning from observing or knowing about drownings in period $t-1$ reduces participation in swimming activities in period $t$. Across a wide array of specifications in conducting the Granger-Simms causality tests for endogeneity, we conclude that there is no compelling support for the "fear of drowning" hypothesis. The results show that there is no evidence of endogeneity in our data.

\section{Discussion}

The foregoing empirical analysis establishes a clear and unambiguous statistical relationship between competitive swimming and drowning. The results demonstrate convincingly that the effects of small increases in participation rates in competitive swimming are substantially larger on black drowning events than on white drowning events. In a critical sense, then, the research advances our scientific knowledge about a key health outcome in a world where there are many preconceptions and tightly held beliefs about the underlying causes of racial disparities.

The intuitive explanation for the inverse relationship between competitive swimming and drowning rates is that competitive swimming is associated with the labor market for lifeguards. This linkage is not directly tested in the current model that is based on a pooled-cross-section time series data set. However, supporting evidence comes from annual data from 1972 until the present on lifeguard employment rates and downing rates by race, gender and ethnicity.

Lifeguard employment is measured annually from the Current Population Survey's March Supplement. The occupation with the category "lifeguards" only goes back to 1968. There were multiple changes in the aggregation of the subcategory until 1972. Accordingly, the measure used in this analysis is based on the coding for lifeguards since 1972 through 2015 . We use 2010 occupation codes and the cross walk between previous years to obtain lifeguard employment counts by race, by gender, by year. The lifeguard employment rate is the ratio of the number of lifeguards employed to the number of persons in each race/gender category.

Figure 2 reports the result of plotting the drowning rates for blacks ages 5-14 against the lifeguard employment to population rates in each year. On the $\mathrm{x}$-axis is the lifeguard employment to population rate and on the y-axis is the black male drowning rate. The fitted values using the best n-degree polynomial show that for all but the highest rates of lifeguard employment, black male drowning rates are higher when associated with white lifeguards than when associated with black lifeguards.

Clearly increases in lifeguard employment reduce drowning rates. But, are there differences within racial groups of the effects of lifeguarding on drowning rates? 


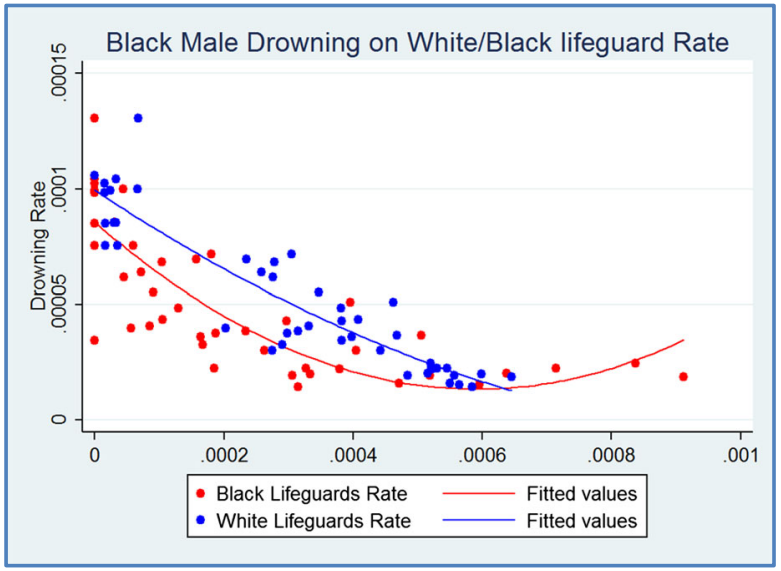

Fig. 2 Black male drowning on white/black lifeguard rate

Table 4 reports the results of estimating a simple model of drowning rates by race and gender as a quadratic function of within-race lifeguard employment rates. We control for college completion rates and summer Olympic year dummy variables, measured by whether there were blacks on the Olympic swimming team in a given year. ${ }^{14}$

Table 4 reports the marginal effects and the elasticities associated with increases in the within-racial-group changes in lifeguards. The intercepts for the black male and black female equations are about twice those for whites, confirming that there are higher drowning rates for blacks than whites.

The marginal impacts are slightly larger for black males than they are for white males. The elasticities evaluated at the means are almost five times as large for black males as they are for white males. ${ }^{15}$ The finding that a percentage increase in the number of black lifeguards reduces black drowning rates more than a comparable change for whites is a clue that explains why there is such a large impact of black competitive swimmers on black drowning rates. This suggestive evidence supports the intuitive explanation for the inverse relationship between competitive swimming and drowning rates for blacks and also encourages future research on more complex models that would explain why there might be racially disparate impacts of lifeguarding on black drowning rates.

\section{Directions for Future Research}

This paper provides evidence of a strong inverse relationship between black competitive swimming rates and black drowning rates. There remain, of course, many

\footnotetext{
${ }^{14}$ Alternative model specifications fit the curves to the nth order polynomial and include dummy variables for whether the year is a summer Olympic year; whether Blacks won gold medals (2000, 2008); whether Blacks were on US Olympic team (2000, 2004, 2008, 2012; whether the USA wins 100 free $(72,76,84,88,2012)$; whether the summer Olympics were held in USA $(84,96)$; or whether the USA participated in Olympics $(72$, $76,84,88,92,96,2000,2004,2008,2012)$. The results are comparable to those in Table 4.

${ }^{15}$ Slopes and elasticities are larger for white females than for black females, but these differences are based on insignificant coefficients on lifeguards in the quadratic model for drowning among black females.
} 
Table 4 Effects of lifeguard employment on drowning rates, 1972-2015

\begin{tabular}{|c|c|c|c|c|c|}
\hline & (1) & (2) & (3) & (4) & (5) \\
\hline & All sample & White males & White females & Black males & Black females \\
\hline \multicolumn{6}{|l|}{ Variables } \\
\hline lifeguards & $\begin{array}{l}-0.0136 \\
(0.0242)\end{array}$ & $\begin{array}{l}-0.0446 * * * \\
(0.00884)\end{array}$ & $\begin{array}{l}-0.0111 \text { *** } \\
(0.00301)\end{array}$ & $\begin{array}{l}-0.0580^{* *} \\
(0.0248)\end{array}$ & $\begin{array}{l}-0.00221 \\
(0.00675)\end{array}$ \\
\hline lifeguards2 & $\begin{array}{l}30.54 \\
(27.85)\end{array}$ & $\begin{array}{l}61.39 * * * \\
(12.51)\end{array}$ & $\begin{array}{l}14.59 * * * \\
(4.522)\end{array}$ & $\begin{array}{l}82.31 * * * \\
(25.41)\end{array}$ & $\begin{array}{l}1.295 \\
(6.923)\end{array}$ \\
\hline college & $\begin{array}{l}-0.000163 * * * \\
(2.44 \mathrm{e}-05)\end{array}$ & $\begin{array}{l}-0.000136^{* * *} \\
(1.32 \mathrm{e}-05)\end{array}$ & $\begin{array}{l}-2.31 \mathrm{e}-05^{* * *} \\
(3.52 \mathrm{e}-06)\end{array}$ & $\begin{array}{l}-0.000366^{* * *} \\
(3.50 \mathrm{e}-05)\end{array}$ & $\begin{array}{l}-4.87 \mathrm{e}-05^{* * * *} \\
(7.14 \mathrm{e}-06)\end{array}$ \\
\hline blk_on_olympic & $\begin{array}{l}2.69 \mathrm{e}-06 \\
(5.09 \mathrm{e}-06)\end{array}$ & $\begin{array}{l}5.98 \mathrm{e}-07 \\
(1.56 \mathrm{e}-06)\end{array}$ & $\begin{array}{l}5.86 \mathrm{e}-07 \\
(5.65 \mathrm{e}-07)\end{array}$ & $\begin{array}{l}3.06 \mathrm{e}-06 \\
(5.30 \mathrm{e}-06)\end{array}$ & $\begin{array}{l}6.05 \mathrm{e}-07 \\
(1.44 \mathrm{e}-06)\end{array}$ \\
\hline Constant & $\begin{array}{l}6.62 \mathrm{e}-05^{* * *} \\
(4.43 \mathrm{e}-06)\end{array}$ & $\begin{array}{l}6.82 \mathrm{e}-05 * * * \\
(3.13 \mathrm{e}-06)\end{array}$ & $\begin{array}{l}1.43 \mathrm{e}-05 * * * \\
(7.19 \mathrm{e}-07)\end{array}$ & $\begin{array}{l}0.000131^{* * * *} \\
(4.94 \mathrm{e}-06)\end{array}$ & $\begin{array}{l}2.50 \mathrm{e}-05^{* * *} \\
(1.16 \mathrm{e}-06)\end{array}$ \\
\hline Marginal Effects, $d y / d x$ & -0.0123 & -0.0424 & -0.0109 & -0.0495 & -0.0022 \\
\hline Elasticity, dlny/dlnx & -0.0010 & -0.0024 & -0.0002 & -0.0112 & -0.0001 \\
\hline Observations & 180 & 45 & 45 & 45 & 45 \\
\hline R-squared & 0.436 & 0.953 & 0.897 & 0.916 & 0.820 \\
\hline
\end{tabular}

Bold coefficients added for emphasis. Robust standard errors in parentheses $* * * p<0.01, * * p<0.05, * p<0.1$

unanswered questions. There is a long legacy of segregated swimming pools in the United States. Since the passage of Title III of the US Civil Rights Act that banned segregation in public facilities, there has been a dramatic decline in drowning rates. But, both black and white drowning rates declined over the past 50 years with the racial gap in drowning rates remaining largely unchanged. Future research is required to address the question of why racial disparities in drowning rates persist. It is entirely likely that the desegregation of public pools had the unintended effect of expanding private pools and swimming instruction among whites, reducing white drowning rates at the same time greater access to swimming pools among blacks reduced black drowning rates. The result is that dramatic reductions in both black and white drowning rates appear to be related to desegregation even when racial gaps in drowning rates remain unchanged.

There may be other explanations for the sharp drop in black and white drowning rates since the 1960s. Possible policy induced impacts include: fencing requirement around pools; improved lifeguard training; ordinances requiring lifeguards on public beaches and hotels; and swimming instruction in middle schools.

Future economic research should explore these critical unresolved questions, especially those related to the dynamics of labor markets for lifeguards. Further evidence might uncover relationships between swimming coaches' beliefs and perceptions about blacks' swimming ability and racial disparities in competitive swimming. At this point, however, there is no evidence upon which to rule out the core finding of this paper: a strong empirical relationship between black drowning rates and competitive swimming. 


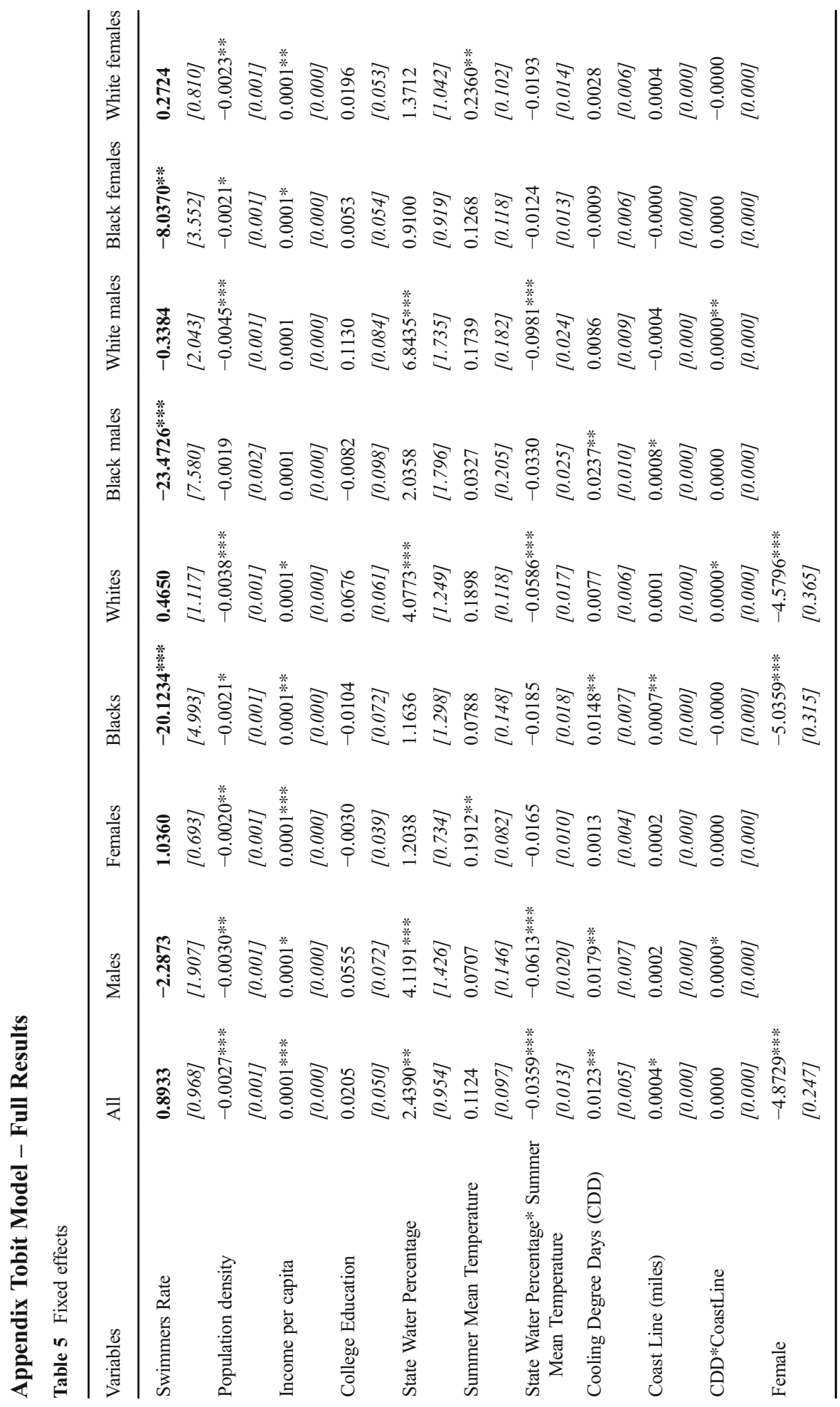




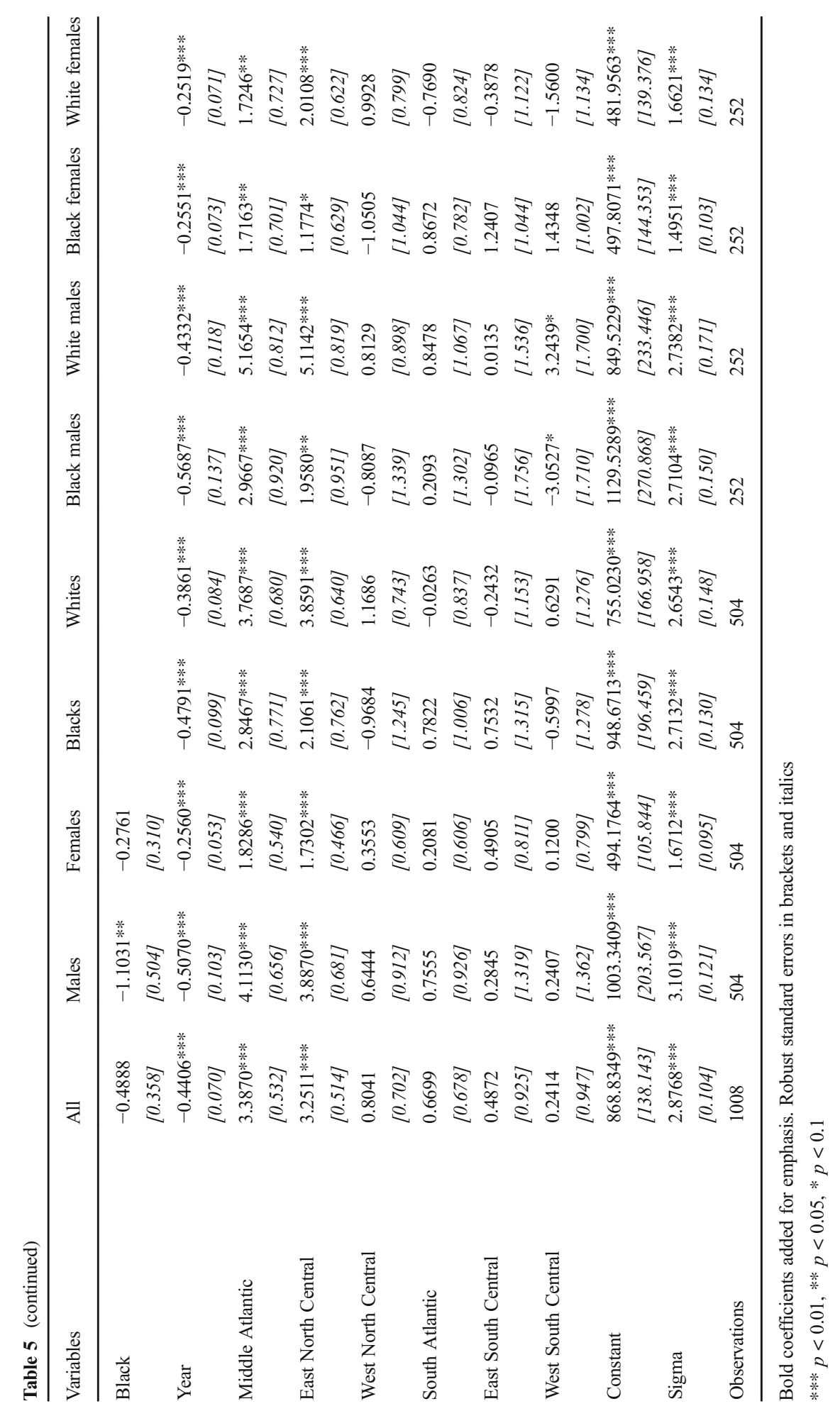




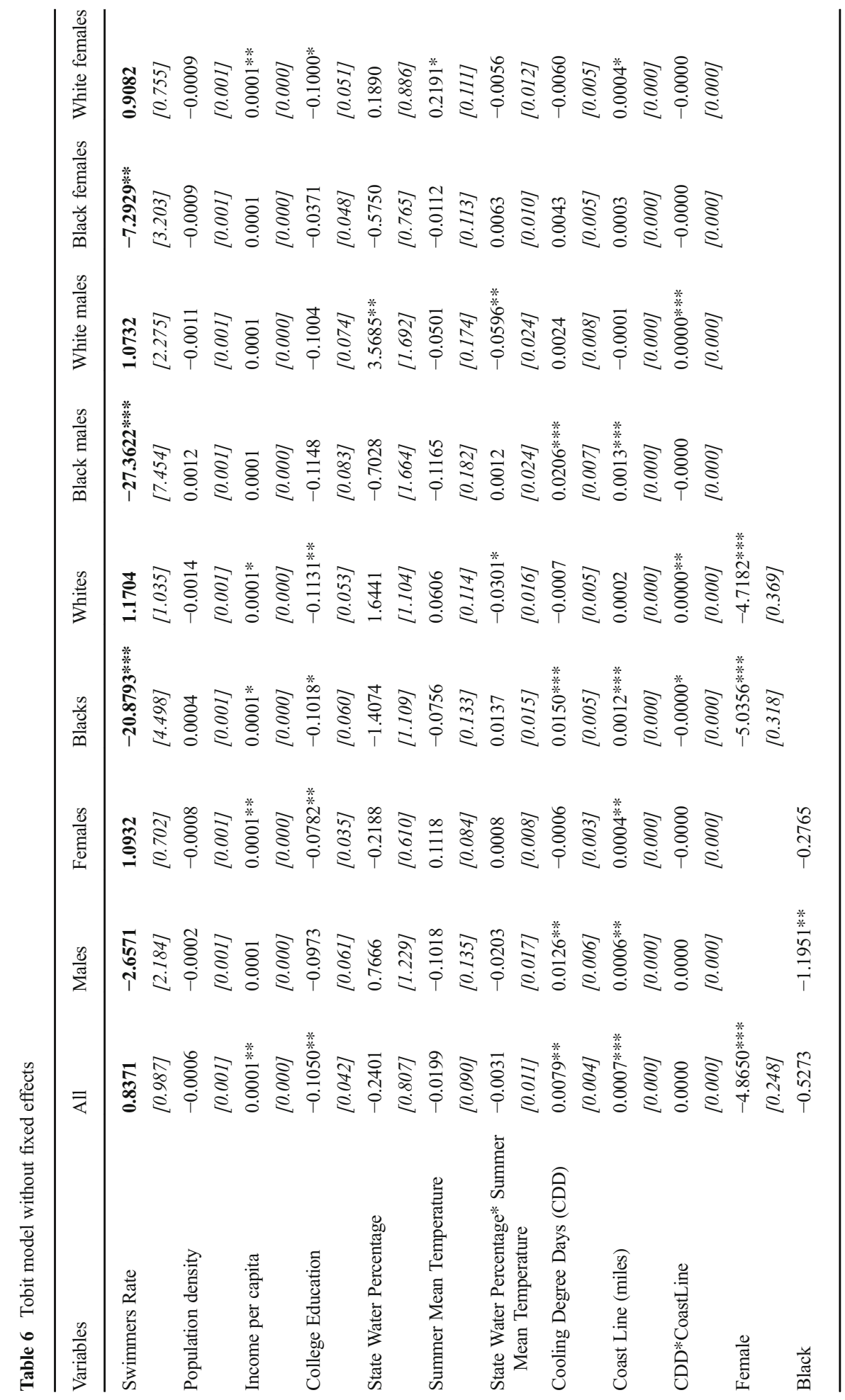




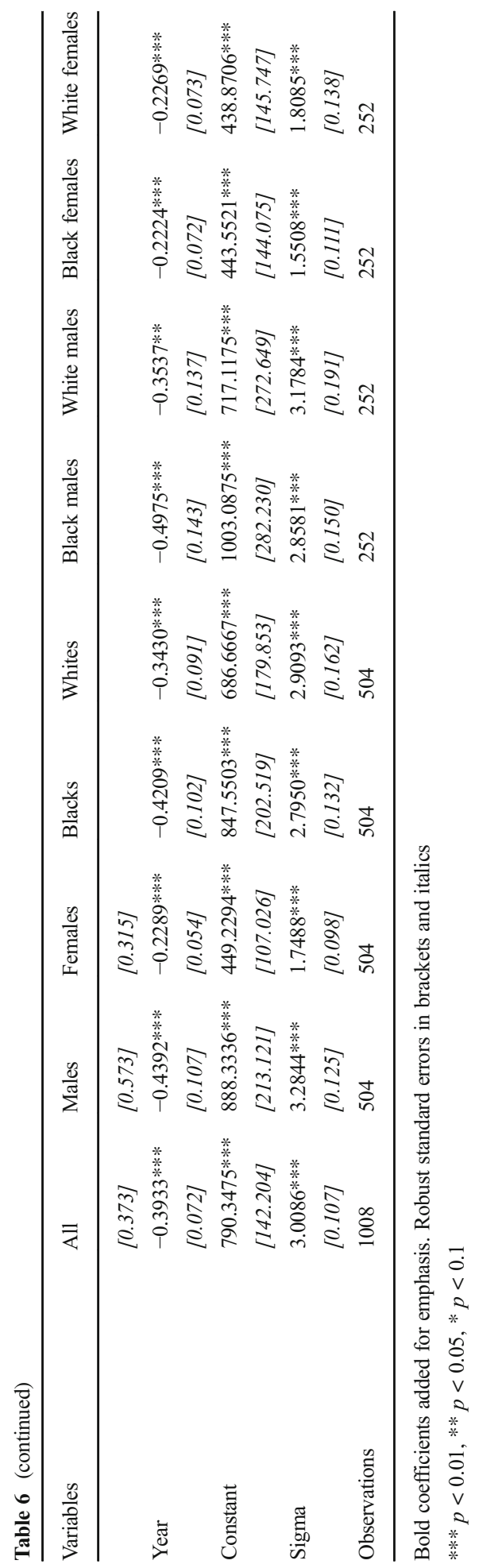




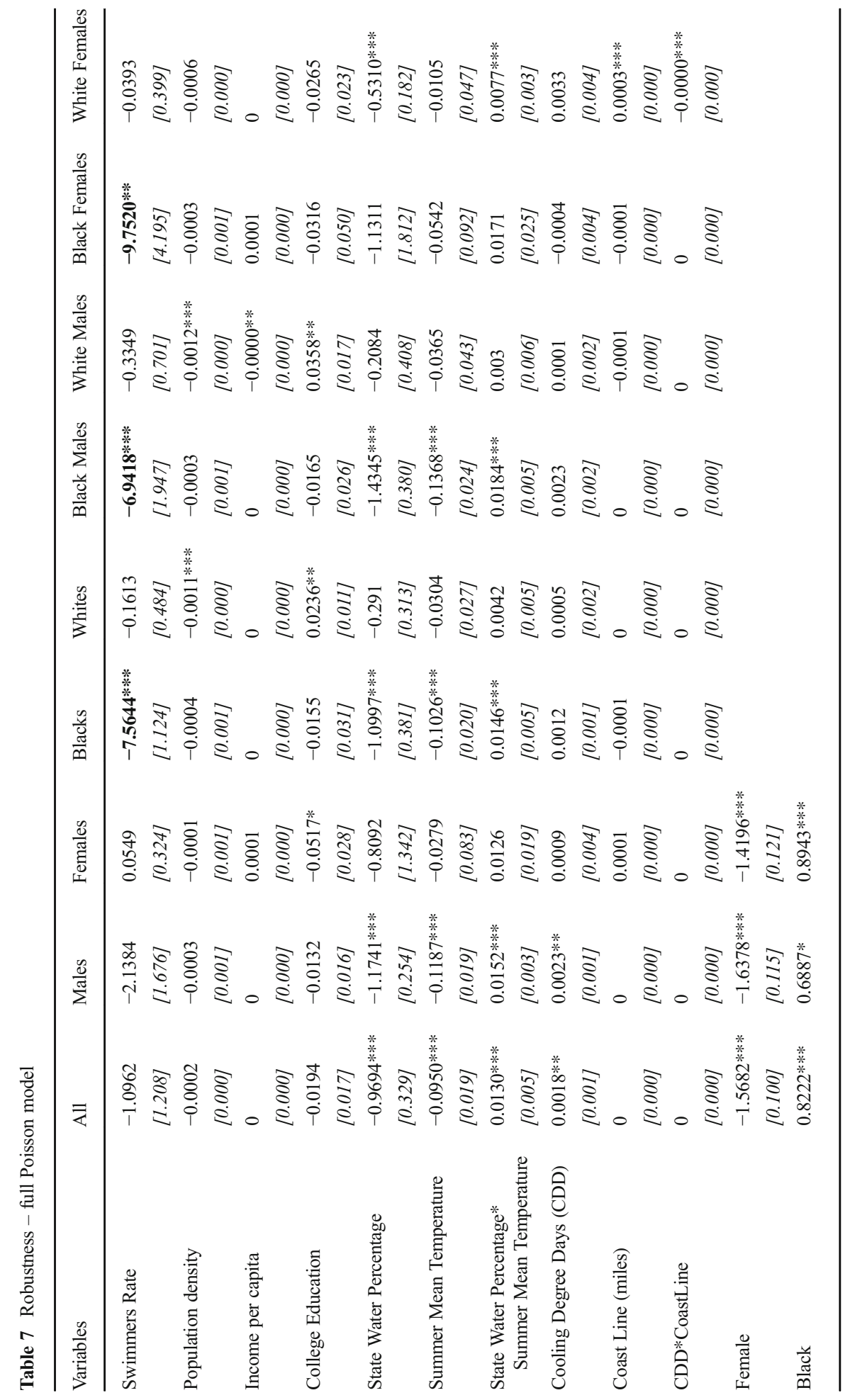




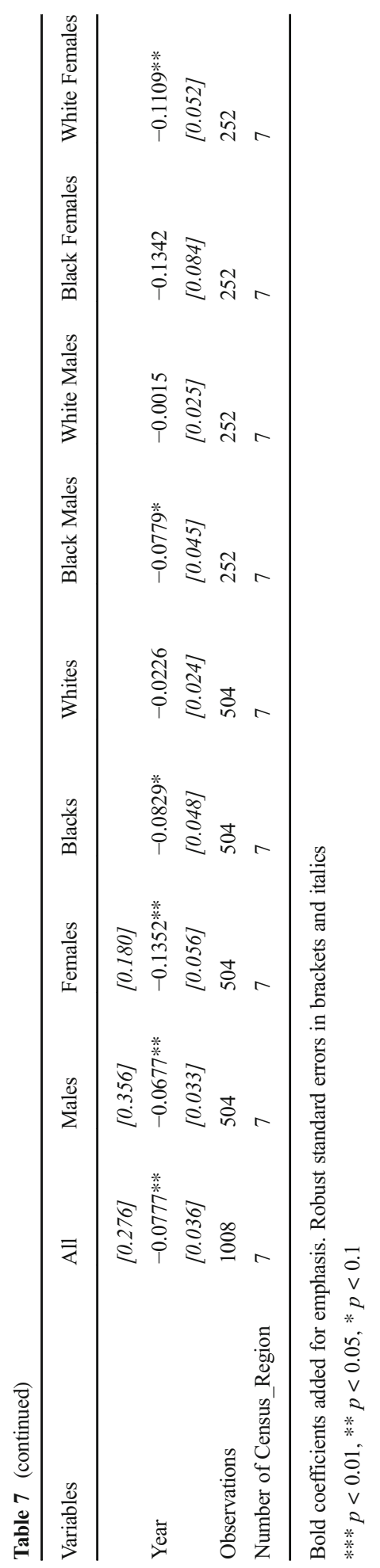




\section{References}

Bejan A, Jones EC, Charles JD. The evolution of speed on athletics: Why the fastest runners are black and swimmers white. International Journal of Design \& Nature \& Ecodynamics. 2010;3(5):1-13.

Borse NN, Gilchrist J, Dellinger AM, Rudd RA, Ballesteros MF, Sleet DA. CDC childhood injury report: Patterns of unintentional injuries among 0-19 year olds in the United States 2000-2006. Atlanta: Centers for Disease Control and Prevention, National Center for Injury Prevention and Control; 2008.

Brenner RA, Committee on Injury, Violence, and Poison Prevention. Prevention of drowning in infants, children, and adolescents. Pediatrics. 2003;112(2):437-9.

Brenner RA, Saluja G, Smith GS. Swimming lessons, swimming ability, and the risk of drowning. International Journal of Injury Control and Safety Promotion. 2003;10(4):211-5.

Brenner RA, Taneja GS, Haynie DL, Trumble AC, Qian C, Klinger RM, Klebanoff MA. Association between swimming lessons and drowning in childhood: A case-control study. Archives of Pediatric \& Adolescence Medicine. 2009;163(3):203-10.

Centers for Disease Control and Prevention. Unintentional drowning: Fact Sheet. Retrieved June 8, 2011, from Centers for Disease Control and Prevention: http://www.cdc.gov/HomeandRecreationalSafety/WaterSafety/waterinjuries-factsheet.html. Accessed 16 May 2011.

Cossrow N. Falkner. B. Race/ethnic issues in obesity and obesity-related comorbidities. The Journal of Clinical Endocrinology \& Metabolism. 2004;89(6):2590-4.

Cowie C, Port FK, Wolfe RA, Savage PJ, Moll PP, Hawthorne VM. Disparities in incidence of diabetic endstage renal disease according to race and type of diabetes. The New England Journal of Medicine. 1989;321(16):1074-9.

DeLuca JR. Submersed in social segregation: The (RE)production of social capital through swim club membership. Journal of Sport and Social Issues. 2013;37(4):340-63.

Fralick M, Denny CJ, Redelmeier DA. Drowning and the influence of hot weather. PloS one. 2013;8(8): e71689.

Hastings DW, Zahran S, Cable S. Drowning in inequalities: Swimming and social justice. Journal of Black Studies. 2006;36(6):894-917.

Hoberman J. Darwin's athletes: How sport has damaged black America and preserved the myth of race. New York: Mariner Books; 1997.

Irwin R, Drayer J, Irwin C, Ryan T, Southall R. Constraints impacting minority swimming participation. 2008. Retrieved April 11, 2011, from USA Swimming Foundation: http://swimfoundation.org/Document. Doc?id=20.

Irwin CC, Irwin RL, Ryan TD, Drayer J. Urban minority youth swimming (in)ability in the United States and associated demographic characteristics: Toward a drowning prevention plan. Injury Prevention. 2009a;15(4):234-9.

Irwin CC, Irwin RL, Ryan TD, Drayer J. The mythology of swimming: Are myths impacting minority youth participation? International Journal of Aquatic Research and Education. 2009b;3(1):10-23.

Irwin C, Irwin R, Martin N, Ross S. Constraints impacting minority ewimming participation PHASE II. 2010. Retrieved April 11, 2011, from USA Swimming Foundation: http://swimfoundation.org/document. doc?id=66.

Irwin CC, Irwin RL, Ryan TD, Drayer J. The legacy of fear: Is fear impacting fatal and non-fatal drowning of African American children? Journal of Black Studies. 2011;42(4):561-76.

Miller JE. The effects of race/ethnicity and income on early childhood asthma prevalence and health care use. American Journal of Public Health. 2000;90(3):428-30.

Murase T, Haramizu S, Shimotoyodome A, Tokimitsu I. Reduction of diet-induced obesity by a combination of tea-catechin intake and regular swimming. International Journal of Obesity. 2006;30(3):561-8.

Myers SL Jr. Hoberman's fantasy: How neoconservative writing on sport reinforces perceptions of black inferiority and preserves the myth of race. Review of the book Darwin's athletes: How sport has damaged Black America and preserved the myth of race. Social Science Quarterly. 1998;79(4):879-84.

Myers Jr SL. In: Chen S, eds. The economics of diversity: The efficiency vs. equity trade-off in Diversity management: Theoretical perspectives, practical approaches, and academic leadership. Hauppauge: Nova Science; 2011. p. 47-62

de Oliveira CAM, Luciano E, Marcondes MC, de Mello MA. Effects of swimming training at the intensity equivalent to aerobic/anaerobic metabolic transition in alloxan diabetic rats. Journal of Diabetes and its Complications. 2007;21(4):258-64.

Rosimini C. Benefits of swim training for children and adolescents with asthma. Journal of the American Academy of Nurse Practitioners. 2003;15(6):247-52. 
Saluja G, Brenner RA, Trumble AC, Smith GS, Schroeder T, Cox C. Swimming pool drownings among US residents aged 5-24 years: Understanding racial/ethnic disparities. American Journal of Public Health. 2006;96(4):728-33.

Scomparin DX, Grassiolli S, Marcal AC, Gravena C, Andreazzi AE, Mathias PCF. Swim training applied at early age is critical to adrenal medulla catecholamine content and to attenuate monosodium l-glutamateobesity-onset in mice. Life Sciences. 2006;79(22):2151-6.

Stephens T. Physical activity and mental health in the United States and Canada: Evidence from four population surveys. Preventive Medicine. 1988;17(1):35-47.

Swimming USA. USA Swimming membership statistics report 2005. USA Swimming: Colorado Springs; 2005.

Swimming USA. 2012 membership demographics. USA Swimming: Colorado Springs; 2012.

Thompson PD, Buchner D, Pina IL, Baladym GJ, Williams MA, Marcus BH, Berra K, Blair SN, Costa F, Franklin B, Fletcher GF, Gordon NF, Pate RR, Rodriguez BL, Yancey AK, Wenger NK. Exercise and physical activity in the prevention and treatment of atherosclerotic cardiovascular disease: A statement from the Council on Clinical Cardiology (Subcommittee on Exercise, Rehabilitation, and Prevention) and the Council on Nutrition, Physical Activity, and Metabolism (Subcommittee on Physical Activity). Circulation. 2003;107:3109-16. http://circ.ahajournals.org/cgi/content/full/107/24/3109

Weiss J. Technical report—Prevention of drowning. Pediatrics. 2010;126(1):178-85.

Wiltse J. Contested waters: A social history of swimming pools in America. Chapel Hill: The University of North Carolina Press; 2007.

Wiltse J. The black-white swimming disparity in America: A deadly legacy of swimming pool discrimination. Journal of Sports and Social Issues. 2014;38(4):366-89. 